\title{
Un asedio al archivo: el adorno y sus texturas en Río de las congojas, de Libertad Demitrópulos
}

Fecha de recepción: 3 de septiembre de 2018 Fecha de aceptación: 6 de marzo de 2019

\section{Resumen}

En el presente artículo, propongo que Libertad Demitrópulos reescribe, en Río de las congojas (1981), las crónicas coloniales con el fin de imprimir en ellas una huella portadora de subjetividades femeninas, alternas con respecto a las existentes en el archivo oficial de su contexto de producción. Dicho procedimiento se logra a través de la resemantización de una categoría específica: el adorno femenino. La novela impugna el sentido hegemónico de esta noción y crea, en su lugar, una nueva poética sobre el adorno capaz de discutir el archivo dominante en los años del terrorismo de Estado.

Palabras clave: Libertad Demitrópulos; Río de las congojas; archivo; adorno femenino;

subjetividad femenina.

\begin{abstract}
In this article, I propose that Libertad Demitrópulos rewrites, in Río de las congojas (1981), the colonial chronicles in order to imprint a trace bearing feminine subjectivities, alternate from the existing ones in the official archive of her production context. Said procedure is achieved through the resemantization of a specific category: the female ornament. The novel challenges the hegemonic meaning of this notion, and creates, in its place, a new poetics about ornament which is able to discuss the dominant archive during the years of State Terrorism.
\end{abstract}

Keywords: Libertad Demitrópulos; Río de las congojas; archive; female ornament; female subjectivity. 


\section{Introducción}

En Mal de Archivo. Una impresión freudiana (1994), Jacques Derrida, al comentar la historia del término griego que se traduce como "archivo", señala que este posee un carácter dual: comienzo y origen, así como ley y autoridad (1997: 9-10). El filósofo francés vincula ambas concepciones: toda búsqueda por el origen conlleva un reconocimiento de la autoridad que lo genera $y$, al mismo tiempo, implica el sometimiento a este principio.

A finales de los años 70 y principios de los 80, América Latina ve aparecer una serie de obras que recuperan un archivo determinado: las crónicas coloniales. Son ejemplos de ello: Terra nostra (1975), de Carlos Fuentes; El arpa y la sombra (1978), de Alejo Carpentier; Deimón (1978) y Los perros del paraíso (1983), ambas de Abel Posse; Lope de Aguirre, príncipe de la libertad (1979), de Miguel Otero Silva; Sor Juana Inés de la Cruz o las trampas de la fe, de Octavio Paz (1982); El entenado (1983), de Juan José Saer, entre otras. En el presente trabajo, me ocuparé de un caso excepcional que se inscribe en esta misma línea: la novela Río de las congojas, de la jujeña Libertad Demitrópulos (1981). Durante la última dictadura militar argentina, Demitrópulos retoma las crónicas con el fin de imprimir, en los discursos fundacionales, una huella portadora de subjetividades femeninas, alternas con respecto a las existentes en el archivo oficial de su contexto de producción. Este procedimiento lo lleva a cabo a partir de la resemantización de una categoría específica: el adorno femenino. Desde mi lectura, las protagonistas de Río de las congojas impugnan dicha noción tal como fue concebida por un orden patriarcal masculino y europeo y crean, en su reemplazo, una nueva. Esta singular poética del adorno femenino es un elemento provocador que asedia y pone en jaque las consideraciones sobre la subjetividad de la mujer resguardadas por "el poder de consignación" (Derrida, 1997: 11) que sirve de fundamento político al archivo dominante en los años del terrorismo de Estado.

\section{Las detractoras de un estereotipo femenino unificador}

La historia narrada en Río de las congojas comienza en 1650, durante el traslado de lo que se conoce como "Santa Fe la vieja" hacia el sur. Desde las barrancas que bordean el río Paraná, Blas de Acuña, mestizo llegado de Asunción para participar en la fundación de Santa Fe (1573), narra retrospectivamente los acontecimientos de la empresa dirigida por Juan de Garay: los vínculos entre esta y la segunda fundación de Buenos Aires (1580), la Rebelión de los Siete Jefes del mismo año y las aberraciones que entraña una guerra entre mestizos e indígenas. Además de ello, y por sobre todo, Blas recuerda a dos mujeres: María Muratore, la criolla a quien ama y que se ve involucrada en las batallas fundacionales, e Isabel Descalzo, la mestiza, costurera de oficio, con quien, a su pesar, contrae matrimonio y forma una familia.

Los escasos trabajos académicos dedicados al estudio crítico del corpus que aquí nos compete se han concentrado, en su mayoría, en el análisis literario de ambas protagonistas. Tal como manifiesta Ricardo Mónaco, Río de las congojas explora la identidad femenina y el lugar social que esta ocupa como producto de tensiones inscriptas en relación con otra esfera de poder: la masculina. Demitrópulos desquebraja el modelo femenino propuesto por el imaginario hegemónico, propio del contexto histórico recreado y del presente de su escritura, dotando a las mujeres de una sexualidad disidente (Mónaco, 2002: 412). Sobre este punto son enriquecedores los aportes de Nora Domínguez Rubio, quien lee en la obra un desafío a la maternidad como institución patriarcal. Por oposición a los textos canónicos de la literatura argentina, reproductores de una figura maternal estereotipada - es decir, sin un yo 
autónomo, definida en relación con su hijo o su esposo-, la novela empodera a las madres, las cuales rehúyen cualquier tipo de designación fija. Argumenta la autora: "Si una familia se constituye por la inscripción del nombre del padre, la novela niega este poder simbólico al inscribir el de una mujer" (2007:372). La mujer referida es la criolla María Muratore, cuya subjetividad se ve atravesada por una serie de rasgos transgresores: libertad en el uso de los placeres, manejo de armas y participación en las batallas, alfabetización, relaciones con el espacio político, independencia en las decisiones. La protagonista no quiere contraer matrimonio, no tiene descendencia, recibe propuestas sexuales de parte de otras mujeres y se desplaza por los espacios siguiendo a Juan de Garay, de quien está enamorada (2007: 372). Estos pormenores textuales componen el material con el que Isabel Descalzo teje un mito sobre las hazañas heroicas de María. A través de su relato, Muratore se convierte en la madre espiritual de los hijos que la costurera tiene con el mestizo Blas de Acuña, y de toda una comunidad, cuando el mito comienza a propagarse mediante la tradición oral a las futuras generaciones. Isabel es la constructora de una tradición forjada a partir de una epopeya heroica femenina. En este sentido, Domínguez Rubio subraya la separación de funciones entre las mujeres: Descalzo representa la narración de la historia, la reproducción y la maternidad biológica; mientras que María representa el hacer histórico, la sexualidad y la maternidad mitológica (2007: 372). En la creación de esta última experiencia maternal, la autora cree que tienen influencia dos modelos femeninos contrapuestos a los valorados por el discurso de la dictadura militar. El primero de ellos es aquel que encarna Eva Perón, madre espiritual de una Nación, quien también comparte con María otras tres coincidencias: el origen ilegítimo, la lucha sociopolítica y varias versiones sobre el destino de su cadáver (2007: 375); el segundo es el de las Madres y Abuelas de Plaza de Mayo, cuyo accionar repolitiza el relato paternalista de la maternidad (2007: 378). Constanza Ramírez agrega que las Madres y Abuelas no solo sirven como fuentes en la construcción literaria de María, sino también en la de Isabel ya que, como el personaje, son las madres de la nueva raza de mujeres latinoamericanas, destinadas a guardar la memoria de sus muertos (2010: 173). Por último, Ana María García se refiere a un tercer tipo de maternidad personificado en la madre de María, Ana Rodríguez: la no legítima, concebida fuera del matrimonio (2005) la cual, amplía Alejandra Nallim, se ve acompañada por el tópico del hijo no deseado (2008: 282).

En conclusión, la novela quebranta una imagen monolítica de la maternidad que encierra a todas las mujeres en una identidad homogénea, circunscripta a su capacidad reproductiva y crea, en cambio, un espacio conceptual en el que conviven varias ideologías sobre esta. Asimismo, traza relaciones sororas entre las protagonistas, debido a que se disputan la construcción de la maternidad y la memoria, pero en un trabajo en conjunto, sin oponerse. De esta manera, plantea ciertas cuestiones centrales sobre el papel que la mujer tuvo en la política y la historia argentinas. Finalmente, al marginar el rol del padre y duplicar el de la madre, postula un imaginario familiar triangular que resiste el asentamiento patriarcal de la ley (Domínguez Rubio, 2007: 375-379). Subvertida la estructura estereotípica de la familia, completa Mara Favoretto, se vuelven atípicos los roles de sus integrantes y los vínculos que mantienen: Blas, a pesar de ser una figura masculina, nunca tiene el poder; Isabel es la mujer que regula la dinámica de la convivencia con su esposo y hace que sea exitosa al incorporar a María como la guardiana y protectora espiritual; existen matrimonios concertados que benefician legalmente a las mujeres, relaciones incestuosas y madres e hijas enamoradas del mismo hombre (Favoretto, 2009: 81). Silvia Tieffenberg suma otros desvíos con respecto al paradigma tradicional familiar: los tres personajes son hijos ilegítimos, las nupcias de Blas y María se realizan sin la aceptación de ella, el mestizo nunca reconoce a Isabel como esposa (Tieffenberg, 1996: 614). Para la crítica argentina, la nueva noción de familia demanda una escritura de la historia que le sea congruente, es decir, que impugne, como lo hace la leyenda sobre María, un relato patriarcal. 
Este hecho revela que "el ámbito familiar, doméstico o privado y el ámbito público político, lejos de pertenecer a compartimientos estancos, son las caras de una misma moneda" (ibídem: 616).

En otro de sus trabajos, Tieffenberg analiza la génesis del personaje de Muratore, al cual entiende como resultado de diferentes líneas discursivas que parten de la época temprana de la conquista rioplatense. Fundamentalmente, se refiere a la carta que Isabel Guevara envía desde la Asunción a la princesa Juana, hija de Carlos V, en 1556. El documento - apunta la autora - es el primero de la época colonial temprana que muestra una figura femenina contraventora: posee la lecto-escritura, se vale del derecho de solicitar una recompensa material para ella y para su esposo, percibe el matrimonio como obstáculo para la acción, entre otros (Tieffenberg, 1993: 952-953). Mientras que gran parte de los escritos masculinos-tales como el cuento "El primer poeta", de Manuel Mujica Láinez- sustituye dicha imagen de Guevara por la de una prostituta distanciada de los roles culturalmente asociados al hombre, Demitrópulos recupera en María Muratore aquel discurso femenino inicial, el de la mujer guerrera e independiente (ibídem: 956). Siguiendo esta lectura, Constanza Ramírez supone que ciertas características de la española son actualizadas tanto en María como en la protagonista homónima de la novela: "el personaje de Isabel de Guevara está desdoblado en estas dos mujeres, puesto que ella realizó la labor de ambas: conquistar una tierra y mantener una tradición" (2010: 173). Esta doble actividad es indagada por Zulma Palermo; para ello, la investigadora salteña recuerda la línea argumental de María Muratore: primero se muestra sumisa al conquistador español, pero luego se rebela contra él y participa en las batallas con los mestizos, quienes, a diferencia de Garay, saben quererla. La protagonista conforma una metáfora del destino de América, destino

(...) que no se encuentra en los indios que la poblaron, ni en los españoles que la pretendieron, sino en los mestizos, mientras los españoles la dañan porque ambicionan el logro de sus propios intereses, los mestizos, sabiéndola suya, la buscan comprensivamente en posesión amorosa. (Palermo, 1982: 17)

Palermo opina que el asentamiento de una estirpe mestiza trae aparejada una concepción del tiempo no occidental: el circular que, en la novela, se encuentra constantemente marcado por uno de los estribillos de Blas de Acuña: "el tiempo simulaba pasar" (1982: 10). Al respecto, Florencia Abbate recuerda los postulados de David Quint en Epic and Empire sobre el nexo entre el eterno retorno y "la épica de los vencidos", por un lado, y el tiempo teleológico y "la épica de los vencedores", por el otro. Es precisamente en esta forma fragmentaria o circular donde los derrotados encuentran la posibilidad de la narración de una historia de resistencia que se muestra bajo el aspecto de insurrecciones periódicas o actos de sabotaje. Para Abbate, la obra de Demitrópulos no responde en su totalidad a ningún paradigma genérico, sin embargo, en virtud de su concepción cronológica, su estructura y la triple opresión que escenifica (de género, de clase y de etnia), puede ser pensada como una narrativa de los vencidos (Abbate, 2015). Existen otros abordajes sobre la hibridez genérica del texto. Hebe de Campanella lo relaciona con la novela de aventuras ya que, a su juicio, Muratore cumple los desafíos prototípicos del monomito del héroe (2003: 116-121), Elisa Calabrese encuentra en Río de las congojas, cuando la narración se detiene en el fluir de la conciencia de los personajes, ciertos procedimientos de la novela lírica (Calabrese, 1994: 69), mientras que Jorge Bracamonte destaca la confluencia de recursos provenientes de las crónicas históricas, el relato testimonial y el melodrama (Bracamonte, 2016: 140). Por su parte, Poderti se detiene en un aspecto de la escritura de la autora jujeña: la capacidad para contrarrestar los lugares de enunciación masculinos que proyectan una visión deformada sobre el universo femenino y que imperan en el canon de la literatura latinoamericana. La autora menciona como ejemplos paradigmáticos a Alejo Carpentier y Gabriel García Márquez (Poderti, 2000: 131). 
En síntesis, las mujeres de Demitrópulos son sujetos culturales fronterizos, corruptores de las concepciones biológicas, esencialistas y misticistas de lo femenino (Nallim, 2008: 12). A lo largo de la novela, Isabel y María logran transgredir los imperativos categóricos impuestos por la episteme de la colonialidad y ocupar esferas de poder. A mi juicio, en este proceso, el adorno femenino, no estudiado hasta el momento, cumple un rol fundamental.

\section{El adorno femenino, ¿una futilidad?}

Antes de realizar un abordaje al texto literario, resulta conveniente esclarecer los múltiples sentidos que el adorno encierra. Para ello, me detendré, en principio, en ciertas aportaciones a la cuestión propuestas por las historiadoras españolas María Milagros Rivera Garretas e Isabel Pérez Molina, quienes se ocupan de los debates que, durante largos siglos de historia occidental, ha suscitado la categoría que nos compete. Los estudios de ambas investigadoras ayudan a revelar cuáles son los significados con los que el orden patriarcal y dominante reviste el adorno femenino, cuáles son aquellos otros que marginaliza y qué propósitos políticos se encuentran ocultos tras estas operaciones.

La problemática del adorno se remonta a la Edad Clásica. Una de las obras más tempranas y significativas que ilustraron la cuestión es Los trabajos y los dias, donde Hesíodo describe el suceso que representa, de acuerdo con la mitología griega, la creación de la primera mujer mortal: el nacimiento de Pandora. Bajo las órdenes de Zeus, Hefesto da cuerpo a la doncella quien, inmediatamente después, es hermoseada por un grupo de deidades femeninas mediante ornamentos y apliques:

La diosa Atenea de ojos glaucos le dio ceñidor y la engalanó. Las divinas Gracias y la augusta Persuasión colocaron en su cuello dorados collares y las Horas de hermosos cabellos la coronaron con flores de primavera. Palas Atenea ajustó a su cuerpo todo tipo de aderezos. (Hesíodo, 1982: 66).

Luego, Argifonte le confiere una lengua engañadora, seductora y "un carácter voluble por voluntad gravisonante" (Hesíodo, 1982: 66). Finalmente, tiene lugar la entrega de ofrendas divinas, las cuales constituyen una "perdición para los hombres que se alimentan del pan" (ibídem). En una nota al pie de la edición de Los trabajos y los días que prepararon para el sello Gredos, Pérez Jiménez y Martínez Díaz afirman que estos dones no aluden a los males aprisionados en la jarra de la mujer, sino a ciertos regalos que, por su encantamiento y belleza, pueden conducir al hombre a su ruina (Hesíodo, 1982: 66). El relato evidencia cómo, desde la época clásica, circula una serie de conceptos vinculados al género femenino que han imperado a lo largo del tiempo en la sociedad occidental: la mujer como producto del trabajo creador de una figura paterna, la mujer como ser volátil, artificial y ornamentado, objeto de deseo del hombre y fuente de peligros para él. Además, es interesante subrayar que, si bien son varios los atributos concedidos a Pandora, el adorno es el primero de ellos y es el único que recibe de otra mujer. Volveré sobre este punto más adelante. El adorno aparece también en La Política de Aristóteles. Rivera Garretas cita uno de sus pasajes: "Se debe aplicar a todos lo que el poeta dijo de la mujer: 'en la mujer el silencio es un ornato, pero no en el hombre"' (Hesíodo, 1982: 63). La falta de palabra femenina conforma un ornamento valorado por la cultura masculina.

La Edad Media y la Edad Moderna realizan nuevas aportaciones. Con el comienzo del cristianismo, apunta Rivera Garretas, los Padres de la Iglesia reprueban los adornos: suponen que estos tienen como único fin atraer y hechizar a los hombres, a quienes 
convierten en sujetos dóciles y maquinales; además, leen en el cuerpo adornado una apuesta por mejorar la obra divina, la cual, en consecuencia, se ve desafiada y amenazada. En esta época, el adorno crea un imaginario sobre lo femenino en el que predomina tanto la mujer hábil en ardides y próxima a la carne -ya presente en la época clásica - como la rebelde y pecadora (Rivera Garretas, 1996: 63-64).

Durante el humanismo de los siglos XIV y XV, se introduce en la discusión un cuestionamiento aún vigente: ¿qué relación guarda el saber con la belleza? Según muchas humanistas - Isotta Nogarola, Laura Ceretta, Luisa Sigea de Velasco-, las mujeres que buscan embellecerse para seducir hombres tienen como destino ineludible una vida adulta circunscripta al casamiento y la maternidad, esferas transformadas por el patriarcado en esclavizadoras de lo femenino. Contrariamente, el trabajo intelectual es la única tarea que les permite ejercer su libertad. Saber y belleza son opuestos en este sentido, pero también excluyentes: ornarse es una frivolidad que impide invertir el tiempo en algo tan provechoso como el aprendizaje de nuevos saberes. En esta etapa, el adorno funda una visión del cuerpo femenino como un estorbo que debe ser, necesariamente, desestimado por la mujer para poder generar espacios de existencia libre. Una respuesta contestataria a tales planteos afirma que las mujeres se adornan para sí mismas regidas por un deseo natural al refinamiento, el cual debe ser respetado; Cristina de Pizán es la representante más acabada de esta postura (Rivera Garretas, 1996: 65-67).

En Europa, el adorno está presente no solo en los tratados medievales y modernos, sino también en los textos jurídicos y leyes suntuarias. Si bien estas leyes persiguen un sentido económico y regulan ambos géneros, una parte sustancial de ellas pretende la normativización del comportamiento sexual de las mujeres a través de pautas impuestas sobre sus vestidos. ${ }^{1}$ La indumentaria, por tanto, hace del cuerpo de estas un locus significativo capaz de encarnar y transmitir prescripciones culturales sobre lo femenino y masculino que permiten reforzar las fronteras de las identidades de género binarias, lo cual alcanza su máxima expresión, para los historiadores del traje, durante el siglo XIX. ${ }^{2}$ Isabel Pérez Molina problematiza esta vinculación entre el adorno y las leyes suntuarias:

Si el adorno femenino se refiriera exclusivamente a la conversión de la mujer en objeto para hacerse atractiva a los hombres, las leyes suntuarias no tendrían ningún sentido, dado que ¿para qué prohibir o castigar algo que refuerza el propio sistema dominante? En este sentido, siguiendo a Michel de Certeau, también es necesario tener en consideración que, la apariencia autorizada de lo "real", es decir, su representación, lo que hace es camuflar la práctica que realmente está detrás del hecho en sí mismo. En el caso del adorno femenino, su versión autorizada, por la cual el objetivo es que las mujeres puedan atraer a los hombres, encubriría el propio deseo femenino más allá de la intervención masculina, como mujer sujeto y en contacto con la genealogía materna. (2004)

La autora resume algunas interpretaciones sobre el significado de la categoría en cuestión que han sido marginalizadas por el orden dominante. En primer término, 1 Son ejemplo de ello las regularizaciones sobre la medida de los escotes o las prohibiciones en cuanto a llamar la atención con los vestidos (Pérez Molina, 2004: 105).

2 Laura Zambrini afirma que "Para los historiadores del traje, fue a partir del siglo XIX que la vestimenta incrementó la división de los imaginarios de lo femenino y lo masculino. En dicho siglo, occidente recreó a través de la moda dos patrones excluyentes en los modos de vestir, uno para los hombres, y otro para las mujeres, y ambos debían connotar valores opuestos". La autora explica que, durante esta etapa, denominada “La Gran Renuncia del siglo XIX”, la indumentaria creó una estética femenina vinculada al adorno y a lo decorativo "como rasgo identitario que a primera vista se diferenciaba de lo masculino” (2010: 131-132). La marcación binaria del género en la estética corporal como resultado de la incorporación de nuevas vestimentas ha ido incrementándose, a juicio de Mariana Daniela Gómez, desde mediados del siglo XX hasta la actualidad (2009: 298). 
la mujer se adorna, tal como argumentó Cristina de Pizán, siguiendo sus propios deseos, como una forma de placer para sí y no para el hombre. En segundo término, el adorno es capaz de vitalizar los lazos femeninos; a juicio de Pérez Molina, esta idea está presente en las primeras lecturas sobre él: “ ¿Es casualidad que sea Atenea la que en el mito greco-romano adorne a Pandora? ¿Refleja este mito una relación entre mujeres con respecto al adorno femenino que era quizás más evidente en tiempos de Hesíodo?" (2004). Por último, el uso de ornatos, apliques y accesorios comunica a las mujeres con la genealogía materna. Rivera Garretas explica que esto se debe a que dicho uso, al reconocer y realzar el cuerpo de la mujer, evoca la creación de vida desde la carne, es decir, desde la madre: "el gusto por adornarse es una herencia femenina que recuerda que es ella - que es la madre - la creadora del cuerpo, sede y figura de la existencia humana" (1996: 68). Este razonamiento se enfrenta a los preceptos cristianos, según los cuales la humanidad es creada por Dios Padre, sin intervención materna. En síntesis, mientras que, desde el sistema hegemónico patriarcal, el adorno simboliza un desafío contra la obra de Dios y, por ello, debe ser censurado, desde el orden simbólico materno, pone en contacto a las mujeres con el origen femenino de la vida. En su lucha por el sentido del adorno, ambas interpretaciones están disputando a quién atribuir la autoría de la creación (Rivera Garretas, 1996: 63). Plantea la autora:

La cuestión del adorno ofrece, pues, una manifestación de libertad femenina en la historia, una manifestación de amor femenino de la madre que "ignora que todo cuanto nace es obra de Dios", como decía Luisa Sigea de Velasco. Una instancia de libertad femenina en la historia que el patriarcado trunca y trata de reconducir hacia el amor heterosexual y el matrimonio, hacia lo que las humanistas llamaban "esclavitud". El lenguaje que es el adorno femenino resulta un lenguaje peligroso y conflictivo en las sociedades patriarcales, esto es así porque el patriarcado presenta al padre como verdadero autor de la vida. Y porque el saber aprendido de la madre, ellas, que deben olvidar la genealogía materna, deben abandonarlo al dejar de ser niñas - al hacerse eróticamente deseosas y deseables-o transformarlo en medio de interlocución con hombres de su entorno. De ahí que el adorno femenino sea banalizado hasta convertirlo en un lenguaje que no solo no dialoga ya con el origen del cuerpo femenino sino que lo que debe hacer es seducir a los hombres. (...). Un cuerpo femenino, sin embargo, que cuando sabe percibir el sentido nupcial del adorno, lo disfruta para sí y mantiene viva la estructura simbólica de relación de la hija con su madre; una estructura que existe aunque se recuerden o se entiendan pocos de sus códigos, una descodificación de la que el patriarcado se nutre. (Rivera Garretas, 1996: 68-69)

Las reflexiones de Rivera Garretas y Pérez Molina evidencian que el adorno, lejos de ser una simple futilidad, conforma una noción política de gran envergadura: en el gesto de referirse al origen del cuerpo femenino, rememorar la obra de creación materna y fomentar lazos orgánicos entre madre e hija, este se erige en un lenguaje con alcances sociales y políticos que discute el orden patriarcal, censurador del amor de y hacia la madre (Irigaray, 1985: 16).

El adorno también ha sido abordado con profundidad desde el feminismo materialista. En el marco de esta teoría, Iris Marion Young publica On Female Body Experience: "Throwing Like a Girl" and Other Essays (1990) donde, luego de analizar la forma en que ciertas modalidades de existencia corporal femenina, ${ }^{3}$ fundadas por el orden

3 Young postula que el orden patriarcal crea, fundamentalmente, tres modalidades de existencia corporal femenina: 1. Transcendencia ambigua: la mujer es parcialmente trascendental, ya que no mantiene una relación de unidad con su cuerpo, sino que lo percibe como un objeto en el que, a menudo, se siente incómoda. 2. Inhibición del cuerpo: por lo general, ella no confía en su capacidad física para cumplir ciertas metas. Consecuentemente, desarrolla una timidez corporal: vive su cuerpo como una carga que debe ser arrastrada y protegida. 3. Unidad discontinua: en muchas actividades que exigen la participación activa y la coordinación del cuerpo como un todo, la mujer tiende a focalizar 
patriarcal, conducen a la mujer a un proceso de cosificación e inhibición física, caracteriza la ropa y los accesorios, principalmente las joyas, como elementos que pueden alimentar y/o resistir tal objetivización.

En "Women Recovering our Clothes", el cuarto capítulo del referido texto, Young explica que la vestimenta y sus adornos son una respuesta a la mirada voyerística masculina, ya que esconden aquello que la norma considera fallas corporales 0 acentúan las zonas fetichizadas (como por ejemplo, los senos o el cuello), es decir, hacen del cuerpo femenino un objeto deseable para el hombre. Además, son comercializados mediante una moda patriarcal constructora de un paradigma de la hembra perfecta y bien vestida, el cual contamina de culpa al placer que cualquier mujer puede llegar a experimentar si se identifica con dicho estereotipo ideal.

Sin embargo, de acuerdo con la filósofa estadounidense, las imágenes que aparecen en revistas de moda, películas o programas de televisión no siempre crean el canon de belleza opresor sino que, frecuentemente, permiten la entrada a un mundo de fantasías en el que la mujer lleva a cabo un proceso lúdico con las vestiduras (juega con la forma, con los colores, con los estilos) y se piensa como protagonista de distintas narrativas de su invención. La capacidad de la ropa para convocar a la imaginación femenina es subversiva, porque desestabiliza el lenguaje de la racionalidad en un sistema donde este lenguaje sustenta la dominación:

Part of the pleasure of clothes for many of us consists of allowing ourselves to fantasize with images of women in clothes, and in desiring to become an image, unreal, to enter an intransitive, playful utopia (...). There are ways of looking at oneself in the mirror that do not appraise oneself before the objectifying gaze, but rather desubstantialize oneself, turn oneself into a picture, an image, an unreal identity (...). In such a fantasy we do not seek to be somebody else. (Young, 1990: 186)

Asimismo, al igual que las historiadoras españolas, Young considera a la vestimenta un componente central en la creación de vínculos femeninos:

Clothes often serve for women in this society as threads in the bonds of sisterhood. Women often establish rapport with one another by remarking on their clothes, and doing so often introduces a touch of intimacy or lightness into serious or impersonal situations (...). I love my sweater, and in letting you wear it you wear an aspect of me, but I do not possess it, since you can wear it (...). As the clothes flow among us, so do our identities; we do not keep hold of ourselves but share (...). And in regarding to other women through our clothes we do not just exchange; we let or do not let each other into our lives.(Young, 1990: 188).

De esta manera, la autora plantea la posibilidad de que, en primer lugar, las mujeres sustituyan la percepción masculina con la que se observan a sí mismas por la suya propia y, en segundo lugar, recuperen un placer por la ropa y los adornos no corrompido por la falocracia en el que encuentren formas de liberación.

Estas constelaciones de sentidos asociadas a los adornos son puestas en juego en la novela de Demitrópulos. Me dedicaré al análisis de esto último en los siguientes apartados.

el movimiento en una parte corporal determinada dejando al resto inmóvil. La subsección del cuerpo que trasciende hacia una meta está en desunión con aquellas otras zonas que permanecen fijas. La autora hace hincapié en que la mayoría de estos comportamientos son resultado de conductas que le han sido inculcadas desde niña, de la falta de práctica física o de la forma en la que se ha visto obligada a trasladarse en el espacio, esto es, con posturas muy cerradas en comparación con las de los hombres. 


\section{La destrucción de una antigua poética: María Muratore y la mujer- adorno}

María Muratore ocupa, en la novela, espacios subalternos: es criolla, es ilegítima, es mujer y es pobre. No obstante, es respetada por la comunidad en virtud de una destreza particular: maneja el arcabuz "mejor que muchos hombrecitos" (Demitrópulos, 2009: 39), hecho que le permite intervenir en los enfrentamientos armados junto con mestizos y criollos, quienes resisten tanto la invasión española como la indígena. Esta cualidad de Muratore es censurada por Blas de Acuña, quien rechaza a la mujer que domina las armas y, en cambio, sueña con la que personifica la belleza a través de vestidos y accesorios:

No quería mediamujer sino aquella María hembra hermosa, vestida con falda y mantilla de tul, oliendo a lo que tiene que oler una mujer, rosada de piel y de andar grácil, brillándole los ojos y rompiendo una frutilla en los labios. Esa mujer quería yo (...). De su mano caliente recuerdo un lunar en el índice; de su hombro una bruma; de su ombligo un pozo de dulzura; de su cuello un pañuelo; de su pelo un reverbero azul. (Demitrópulos, 2009: 43)

Desde esta perspectiva masculina y cosificadora, ${ }^{4}$ el cuerpo femenino es un territorio fragmentado cuyas partes han sido conquistadas y sustituidas por un adorno, el cual hace de la mujer una mera escenografía destinada a satisfacer al sexo opuesto. Además, existen otros rasgos propios de esta imagen femenina: se encuentra circunscripta a los ambientes domésticos, es indefensa y necesita del cuidado del hombre (Demitrópulos, 2009: 70).

Bajo esta misma mirada, Blas introduce en la novela a otra de las protagonistas, Ana Rodríguez:

Por más disimulo que ponga en evitar la curiosidad y la condena del vecindario, se le descubre por la fiebre de los ojos y ese olor a guayaba madura. La veo pasar con su saya lila (o azul o salmón), chapines de lo mismo, enguantada la mano, rebozo bordado, derramando ese misterio por el que ya no es fláccida, ni torva, ni mustia, ni ausente, sino una mujer que va al encuentro de su mejor conquista. (Demitrópulos, 2009: 26)

Estos adornos ocasionan un efecto de imantación en los personajes masculinos y en los femeninos: María, por ejemplo, admite verse cautivada por ellos. A pesar de esta atracción, la relación entre ambas mujeres es rencorosa, ya que son contrincantes en la disputa por el amor de Juan de Garay. Además, la rivalidad se agudiza en virtud del parentesco que mantienen: Ana es la madre de María. Los adornos colaboran en la definición del resultado de la contienda: mientras Ana es "ducha en sortilegios y perfumes" y "experta en modas" (Demitrópulos, 2009: 55), Muratore solo cuenta con algunas "ropas ordinarias" (ibídem: 38). La maestría de la primera en el uso de estos ornamentos es uno de los encantos primordiales que le permite convertirse en la amante del conquistador (ibídem: 27). Por consiguiente, el adorno en su sentido patriarcal, es decir, destinado a la seducción del hombre, actúa como instrumento corruptor de los vínculos femeninos, sobre todo, los maternos y filiales.

Asimismo, Muratore incorpora los adornos cuando decide emprender una travesía a Buenos Aires junto con Juan de Garay, a quien aún busca enamorar: "Me embarqué con el anillo y algunas armas. Ropa llevaba poca, que galas no tenía. Eso sí: puse tijeras para ensortijarme el pelo y unos pañuelos de Holanda para lágrimas, que

4 No todas las miradas masculinas cosifican a la mujer. Tanto Arturo Cabrera, el negro de Guinea, como Alonso Martínez, padrino y amante de María, por ejemplo, pueden actuar como contrapunto de Blas. 
nadie sabe lo que le depara el destino" (ibídem: 104). Este ejemplo muestra a una María adoctrinada por los ritos del "mito de la belleza", 5 lo cual equivale, de acuerdo con Naomi Wolf, a ser una mujer políticamente sedada (1991: 165). Precisamente, es este estado de sedación el que define a la protagonista mientras mantiene relaciones con el Hombre del Brazo Fuerte. Una escena ilustrativa de ello transcurre en La Nao Perdida, el supuesto hospedaje que él reserva para Muratore y que es, en realidad, una prisión. Allí María sufre una alienación sensorial y cae en un sueño profundo guiado por el embrujo de Régine de Birmania, cómplice de Garay: "La voz de Régine era espesa y se ahuecaba hasta tocar mis sentidos, adormeciéndolos. Como efecto del vino que me dieron, fui entrando en un lento sopor" (Demitrópulos, 2009: 109). Progresivamente, se adentra en los interiores de esa casa laberíntica hasta que termina perdiéndose por completo: "Luego volvía a encontrar los corredores cada vez más estrechos y húmedos y escuchaba un solo maullido largo, enamorado y furioso" (ibídem: 110). Seducida y, más tarde, abandonada por su opresor, María es, en esta instancia, objeto del consumo masculino. Cabe cuestionarse: ¿cómo consigue Garay sumergir a Muratore en dicho estado de letargo prolongado?, ¿en qué elemento(s) reside la fuerza de dominación del hombre sobre la mujer? No debemos soslayar que, aunque con menor frecuencia que los adornos femeninos, los masculinos también hacen su aparición en la obra. Dice Blas de Acuña sobre el fundador de Santa Fe:

Era un "aba" valiente y de refinamientos. Que el vestir. Que el hablar. Que el puro encantar a las mujeres. Algo tendría, además, para que ellas no se le resistieran. Barba tenía rubia y enrulada, que sobaba con dedos finos y pálidos. Y ojos claros que-iAy del ay! - serían los pendencieros que me robarían lo que yo amaba (...). Si sería galante que se enguantaba para ir a misa o de visita, yél todo era un dechado de prolija vestidura: su terciopelo labrado, su coleto acuchillado, su camisa de ruán, su sombrero, y las calzas y el jubón de raso. (Demitrópulos, 2009: 92)

Tal como lo advierte Blas, la protagonista se deja embelesar por dicho cuerpo adornado - "el cabello le caía con esa gracia que a toda mujer rendía" (Demitrópulos, 2009: 104)-, por lo cual se convierte en una especie de autómata que acata, sin objeciones, las exigencias de Garay. En conclusión, los adornos masculinos adoptan la forma de armas sedantes que desproveen a la mujer de su voluntad y autonomía, mientras que los femeninos -bajo el control del hombre- y el interés de ella por vestirlos son pruebas de tal aletargamiento.

Finalmente, Muratore consigue rebelarse contra esta autoridad que intenta subyugarla: encuentra una manera de escapar de la prisión, disimula su identidad, compra una barca que le permite huir río arriba e incluso mata a dos hombres de Garay. Pero la rebelión de María no solo está marcada en el texto mediante estas evidentes acciones, sino también a través de un cambio, narrado muy sutilmente, en la forma en la que la novela trataba, hasta el momento, la problemática del adorno femenino. En principio, una vez en libertad, los adornos de Muratore comienzan a despedazarse: escapa de la prisión "En composturas de ropas y atuendo que se me habían ajado" (Demitrópulos, 2009: 124). Más adelante, esconde aquellos que aún porta: "llevaba toda mi cabellera oculta debajo de mi gorra sucia, alpargatas y unos pantalones remendados" (ibídem: 129). Asimismo, ya consciente de que solo fue "uno de los tantos caprichos" (ibídem: 128) del conquistador español, María pierde su antiguo interés por adornarse: "Compré armas. Las negras querían enseñarme a vainillar, a repulgar pastelitos, a aderezarme el pelo. Pero me aburría. Esas cosas no me conformaban" (ibídem: 125). Por último, la fuerza de imantación que caracteriza a los adornos masculinos se desintegra apenas comienza la rebelión de Muratore, a quien, luego de

5 En El mito de la belleza (1991), Wolfapunta que el fundamento de este mito es un ideal femenino inalcanzable, "la dama de hierro", edificado y perpetuado por el sistema patriarcal el cual violenta y desmerece a las mujeres por no poder encarnarlo y, de esta manera, afirma y garantiza su lugar dominante. 
este suceso, ya no logran dominar: "Estaba dispuesta a no dejarme intimidar por las águilas ni los aguiluchos del escudo; tampoco por esta letra llena de curvas y finura que tan prolijamente dibujaba aquella diestra mano. Mucho menos por el perfume que bien conocía" (ibídem: 126).

“¿Tiene la mujer derecho sobre su cuerpo y dispone de albedrío?" (ibídem: 128), se preguntan las protagonistas de la novela. A raíz de lo desarrollado hasta el momento, concluyo que la obra impugna la categoría de adorno tal como fue construida por un sistema hegemónico masculino y europeo: expone la esterilidad de aquellos ornamentos y apliques que despersonalizan a las mujeres, las vuelven enemigas entre sí o escenarios para el goce del hombre. Esta ruptura de la imagen "mujeradorno" y el vaciamiento de poder de los adornos masculinos constituyen operaciones fundamentales en Río de las congojas, porque son índices de la lucha femenina contra un sistema que asfixia, pero también porque son condiciones necesarias para llevarla a cabo y recuperar así la agencia sobre el propio cuerpo y la facultad de elegir. La propuesta de la novela no finaliza aquí; exhibe, además, una instancia propositiva: la creación de una nueva poética sobre el adorno femenino.

\section{La creación de una poética: Isabel Descalzo y el adorno como nuevo lenguaje}

La voz de Isabel Descalzo no se deja oír hasta el final de la novela:

Estuve callada, no sin argumentos. No es que no llame la atención con mi cabello rojizo y mis ojos verdes. Algo había siempre que me empujaba para atrás obligándome a desaparecer. Mucho tengo en mi memoria para contar aunque algunos crean que alguien aparentemente frágil como Isabel Descalzo debe pasar sin dejar huellas. (Demitrópulos, 2009: 135)

El pasaje es revelador de varios ejes trabajados en el texto: el silenciamiento impuesto sobre la mujer, el cuerpo como única vía posible para visibilizarla, la huella personal que esta puede - o que le es permitido-dejar en la historia. Isabel logra combatir, gracias al ejercicio de un poder en particular - su habilidad literaria-, esa fuerza coercitiva que, según dice, la conduce a una desaparición. Como hemos apuntado anteriormente, en su afán de concederle un origen común a los hijos y nietos que tiene con Blas, Descalzo crea un relato mítico a partir de las hazañas heroicas - ¿recordadas?, ¿inventadas? - de Muratore, a quien instala como madre espiritual de su descendencia. El mito es transmitido por los miembros de la familia de Descalzo a través de la tradición oral. Como resultado, la huella que la mujer imprime en la Historia es cardinal: ella es la constructora y protectora de la memoria colectiva de su pueblo. Esta labor política social de Isabel se lleva a cabo en la creación de una nueva poética sobre el adorno femenino.

En primer lugar, es llamativo el modo en que Descalzo describe su oficio de costurera:

Allá se decía que yo colocaba el cinturón como un suspiro detenido; los volados como caminos que surcaban el cuerpo; los moños como conversaciones anhelantes; los entredoses como invitaciones a soñar; las alforzas como promesas. ¿Quién se atrevía a contradecirme cuando medía las costuras de hilván flojo y efectuaba las correcciones a ojo, de un solo golpe de vista, rehaciendo el modelo que yo me había dibujado en el interior de mi cabeza (...) cuando disponía y desplegaba las telas a mi capricho sobre el cuerpo de la clienta, haciéndolas rendir ante mi tijera aquello que mi gusto ordenaba? (Demitrópulos, 2009: 135-136) 
Los cinturones son suspiros; los moños, conversaciones; los entredoses, invitaciones; las alforzas, promesas. Lejos de responder a una función decorativa del cuerpo, el adorno lo viste para hacerlo hablar:

Nadie como Isabel Descalzo conocía lo que una mujer estaba dispuesta a decir con su vestido. Insinuar. Desdecir. Nadie como yo conocía el lenguaje del escote, del canesú o de los pliegues. Echaba mano de ese código con mi destreza propia. Era sabido que arreglaba enojos, disipaba engaños y consolaba viudeces cada vez que entraba con mis tijeras y dedales, en las casas donde me llamaban para encargarme una confección. (Demitrópulos, 129: 136)

El adorno como expresión de la voz femenina tiene una gran presencia en la novela, principalmente, porque Demitrópulos retoma la tradicional equivalencia, basada en la identificación tejido-texto, entre el código de la costura y el código narrativo. El campo semántico que gira en torno a la categoría que nos compete (vestidos, sábanas, manteles, mantillas, almohadones, pliegues, dobleces, alforzas, forros, nudos de abejas, pasamanería) se utiliza como metáfora poética de la construcción del mito de Isabel.

En segundo lugar, los ornamentos femeninos no solo son símbolos de la confección del relato mítico, sino también sus protagonistas. Para desarrollar este punto, es pertinente hacer una breve reflexión sobre el papel que los objetos en general tienen en la novela: en Río de las congojas, funcionan como espacios donde el tiempo se condensa. Confiesa Blas:

El tiempo simulaba pasar (...) Penetraba en las arrugas de mis manos y en los resquicios de las cosas que se encargaban de hacerme vibrar. Siempre eran los objetos los que me producían esa vibración: el tarro donde hervía el agua para el mate, las piedras del camino; la reja de la tumba; la canasta que fue del negro Antonio Cabrera; una canoa rolando por el río, mi bota agujereada; el escritorio de S.E.; la cama donde durmió María. Por las cosas me hallo en el tiempo. (Demitrópulos, 2009: 118)

El pasado sobrevive en los restos y fragmentos de la cultura material del universo de lo doméstico. Tal como postula Carlo Ginzburg (1999), la realidad impenetrable y la Historia pueden ser descifradas a partir de ciertas zonas privilegiadas, como lo son los elementos secundarios, es decir, aquellos microobjetos, rastros y huellas poco apreciados, inadvertidos por la observación. Ginzburg propone "un paradigma indicial" (1999: 162): lo marginal es revelador de la Historia y del tiempo.

Isabel Descalzo reactualiza, en sus narraciones, las imágenes del pasado a través de estos objetos secundarios portadores de fragmentos temporales. El elemento vector del mito es un anillo (Palermo, 1982: 18), otro tipo de adorno. Este objeto, que viaja desde el Viejo Mundo y ha tenido, se cree, varios amos - una bruja quemada por la Inquisición, la reina de Inglaterra, una princesa gitana, un hechicero hindú, el corsario John Drake-, llega a María como un regalo de Garay. Al igual que la mayoría de los elementos relacionados con el conquistador, el anillo es fuente de encanto y fascinación: "era un anillo hecho para la ilusión" (Demitrópulos, 2009: 115). La versión de María sobre los acontecimientos ${ }^{6}$ cuenta que ella, perseguida por las autoridades que proceden bajo el mando del Hombre del Brazo Fuerte, vende el anillo para poder afrontar los gastos de su fuga. El discurso mitológico de Isabel respeta esta versión

6 En las antípodas de esta versión femenina sobre el destino del anillo, existe aquella narrada por Blas: María se embarca con Juan de Garay y muere con él en Punta Gorda, a manos de minuanes. Luego del asesinato, se cree que un miembro de esta tribu roba el anillo y lo entrega a un soldado español a cambio de bagatelas. Demitrópulos reescribe aquí la historia oficial de la muerte de Garay tal como figura, por ejemplo, en la crónica de Martín del Barco Centenera. 
y la reescribe: luego de su muerte, la María espectral vaga por el río montada en su caballo blanco en búsqueda de ese anillo del cual una vez se deshizo. Descalzo pone énfasis en este objeto porque permite situar un tiempo determinado, aquel en el que Muratore se deshace del ornato masculino, esto es, del instrumento de sedación y conquista su libertad: "Vendió el anillo para disponer de libertad. Y fue libre todo cuanto supo ser una mujer" (ibídem: 153).

Por último, propongo leer el mito de Isabel como un "texto adornado". El narrador en tercera persona, al mencionar algunos sucesos relacionados con el vivir diario de Isabel, afirma que "de esas cosas no se sabe si [Descalzo] las olvidó por afectarle demasiado o porque las consideraba naturales y, por lo tanto, desprovistas de magia propia como para incluirlas en sus narraciones" (ibídem: 161). La cita desvela las dos operaciones medulares que realiza la autora para aderezar su texto: la invención y el olvido de sucesos. En primer término, Isabel relata hechos artificiales y ornamentados con fantasías y sueños, los cuales suelen contaminarse con motivos recurrentes de las leyendas tradicionales: "Para hacer intervenir a María en el levantamiento de Los Siete Jefes le inventó una relación con uno de los conspiradores, cosa que jamás sucedió" (ibídem: 154). Y más adelante: "El año en que María se embarcó para Trinidad fue cuando llovió ceniza", "cuando María vino florecieron los cardos" (ibídem: 155). En segundo término, Descalzo incluye omisiones intencionadas que son respetadas y mantenidas por la comunidad. ${ }^{7}$ Principalmente, evita la mención del personaje de Ana Rodríguez; este tipo de elipsis sirve a la caracterización de María en dos aspectos. Por un lado, la orfandad se encuentra al servicio de instaurar la referida condición de madre mitológica; Muratore escapa a una genealogía, ella no tiene un origen, porque es en sí misma el origen, el momento cero de la creación: "Soy la semilla: para eso me trajeron. Así, pues, hago tierra y no sofocaciones. Echo raíces" (ibídem: 23). Por otro lado, el hecho representa una forma de liberación: el relato enfatiza la idea de María como "mujer de nadie" (ibídem: 55), sin madre, padre o marido, es decir, sin ningún tipo de ataduras; a propósito, Constanza Ramírez apunta que: "Al no tener madre, ella no tiene linaje ni opresión, es decir, nadie que le haya enseñado la represión que se impone a lo femenino" (ibídem: 170). Si bien existen momentos en que algunos personajes - como Juan de Garay o la familia de Alonso Martínezejercen tal represión sobre María, el mito procura no mencionarlos. En conclusión, por acción del relato adornado de Isabel, Muratore se presenta ante un pueblo como una mujer libre y una madre idealizada y fantasmagórica, guardiana de su familia: "La fueron creando en sus mentes: la finadita era blanca, hermosa, casi había sido la madre de ellos (...). La fueron sintiendo como la protectora de la familia, como la madrina del cielo" (ibídem: 156).

La sustitución de los hechos naturales por los artificiales delimita el sistema de lectura que la obra exige a la familia de Isabel: el mito no apela a una razón clasificadora, sino que es demandante de un acto de fe: Isabel "se apoyaba en varias historias juntas, originadas en distantes lugares del mundo. Basta que esas historias fueran solo misteriosas, improbables y que la gente estuviera, eso sí, dispuesta a creerlas" ${ }^{8}$ (ibídem: 156).

7 El olvido deliberado es una de las bases sobre la que se construye la metodología de la memoria. Elizabeth Jelin y Susana Kaufman sostienen que este "no es ausencia. Es presencia silenciada, negada, y su naturaleza no solo es individual, sino también una construcción social compartida, producto de pactos de silencio grupales y políticos" (2001: 28). Por su parte, Alessandro Portelli resalta la necesidad de descubrir los motivos por los cuales un objeto es desplazado completamente o mal recordado para comprender el sentido profundo del olvido y su "función creativa" (2014: 42, 55).

8 Cabe destacar que el discurso mitológico sobre María no es el único presente en la novela. Los hombres también son protagonistas y constructores de mitos, pero el poder de sus adornos y símbolos se muestra falso e ineficaz: no consigue, como el discurso de la mujer, despertar credibilidad ni crear un espacio de pertenencia (Demitrópulos, 2009: 94). 
Con el tiempo, Descalzo comienza a perderse entre los vericuetos de su obra y delega la actividad narrativa en su única hija mujer, también madre. Cuando la tierra se ve afectada por las fuertes inundaciones y se produce el éxodo de la familia, Isabel comenta sobre ella: "A eso se fue. Comprendía. Así, hasta nunca acabar. Hasta cavar la memoria que es no morir" (ibídem: 165). En este sentido, la novela se dedica al tratamiento de la familia como uno de los sujetos públicos más importantes dentro de la comunidad, ya que compone una suerte de mecanismo que liga temporalidades y subjetividades; tal como la entiende Josefina Ludmer, "La familia en las ficciones es una encarnación específica de la temporalidad: un modo de articular la sucesión, de llenar un hueco de tiempo y de marcar continuidad histórica. Sirve para subjetivizar la memoria, la historia, el futuro, los diferentes pasados" (2002: 110). Dentro de los miembros de esta familia, son las mujeres las protagonistas. El mito de Isabel es una herencia femenina, porque es creado por una madre y es transmitido, tiempo después, por su hija; pero, además, porque adorna sus contenidos con figuraciones y fantasías con el fin de colocar a María Muratore como origen de una comunidad y como responsable de la creación de la existencia humana.

Descalzo teje su obra a partir de una singular poética sobre el adorno. En principio, este es, en Río de las congojas, arma de la palabra de la mujer, elemento lingüístico de su cuerpo. De esta forma, la novela rompe la identidad que el sistema patriarcal, desde la antigua Grecia, ha trazado entre esta categoría y el silencio femenino. Asimismo, los hechos referidos por el mito, sobre todo aquellos que relatan la historia del anillo, prueban que el adorno no esclaviza ni banaliza a la mujer, sino que dice y recuerda su condición de sujeto libre. Por último, la invención que realiza Isabel de relatos sobrenaturales y adornados mediante fantasías crea un lenguaje que coloca a la madre como verdadera autora de la vida y, por consiguiente, conecta una comunidad con su genealogía materna.

\section{Adorno y huella femenina: implicancias políticas}

He dicho, en líneas anteriores, que el mito de Isabel, para ser eficaz, exige a su familia un acto de fe; sin embargo, para el lector, la situación es bien distinta: Río de las congojas desmonta, como quedó apuntado, los mecanismos de la configuración del mito y evidencia su carácter de artificio y montaje. Sobre esta clase de procedimientos, Didi-Huberman, en Cuando las imágenes toman posición, establece que "Mostrar que se muestra no es mentir sobre el estatus epistémico de la representación: es hacer de la imagen una cuestión de conocimiento y no de ilusión" (2008: 77). De esta manera, la novela induce al lector a tomar distancia con respecto al material seleccionado y a reflexionar sobre el sentido político de las construcciones del pasado que expone. Una de las claves para desentrañar estas construcciones se encuentra en la relación que mantiene la obra con el archivo de su contexto de producción.

Entre los modelos insoslayables a la hora de discutir el archivo como categoría teórica se encuentra el de Jacques Derrida. Como he mencionado en la Introducción, el autor explica la historia del término griego "archivo" para exponer su doble carácter:

Arkhé, recordemos, nombra a la vez el comienzo y el mandato. Este nombre coordina aparentemente dos principios en uno: el principio según la naturaleza y la historia, allí donde las cosas comienzan — principio físico, histórico u ontológico-, mas también el principio según la ley, allí donde los hombres y los dioses mandan. (1997:9)

9 Ludmer se refiere a obras literarias publicadas durante el 2000, sin embargo, creo que sus reflexiones sirven para alumbrar este gran sujeto político que es la familia en Demitrópulos. 
Desde su etimología, "archivo" significa el lugar de comienzo y de origen, lo principal y lo primitivo, así como ley, orden, autoridad y poder (1997: 10). A partir de la inclusión del adverbio "allí" en la definición citada, Derrida problematiza la relación espacio/arkhé (1997: 9): es indispensable para el archivo, sostiene, valerse de una cierta exterioridad o domiciliación. La idea de localización está explícita en el origen de la palabra, la cual deriva del arkheion griego, la residencia privada de los magistrados superiores, los arcontes, donde eran depositados los documentos oficiales. Los arcontes no se limitaban a ser guardianes de estos documentos, sino que también constituyían su competencia hermenéutica; por tanto, aquellos ciudadanos a quienes se les reconoce, públicamente, su derecho de hacer y representar la ley son los seleccionados para custodiar e interpretar los archivos. Asimismo, "la función arcóntica" ejerce "el poder de consignación" que sistematiza las partes constitutivas del archivo y garantiza la homologación de signos eliminando una posible heterogeneidad o un "secreto" capaz de asediar su institucionalización; lo cual revela la falsa neutralidad del archivo: este puede reproducir infinitamente el mismo contenido o invisibilizar diferentes sucesos del pasado, puesto que la consignación depende de distintas formas de poder (1997: 11). En conclusión, el archivo se desarrolla "en el cruce entre lo topológico y lo nomológico, del lugar y de la ley, del soporte y de la autoridad" (1997: 11), lo cual, equivale a decir que buscar ese espacio de origen, donde "las cosas comienzan", implica reconocer la autoridad que lo crea y someterse a ella. De ello se desprende una de las tesis medulares del texto: la puesta en orden del archivo determina el orden que el Estado (lugar de autoridad, arkheion) está llamado a garantizar, la totalidad de las estructuras estatales dependen del poder arcóntico y del poder de consignación. El archivo es el fundamento del orden político, "determina de parte a parte lo político como res pública" (1997: 28).

Durante la última dictadura militar, el archivo imperante perpetúa un estereotipo sexual femenino atravesado por los conceptos bipolares machismo/marianismo, madona/prostituta, por lo cual la mujer es socializada como ser sumiso, mera extensión del ego del hombre y parte de la propiedad de este (Bunster, 1991: 43). Particularmente, la construcción social normativizada de la maternidad proponeel tópico de "la buena madre" (Knibiehler, 2001: 54-57), el cual reduce a la mujer a su función biológica reproductiva. Desde el discurso del poder, las madres de soldados o de oficiales militares, quienes crían al niño perfecto y lo entregan a la república, cumplen con el referido paradigma, cuyo antagonismo se ve representado en las Madres y Abuelas de Plaza de Mayo (Favoretto, 2009: 49). Al exigir pública y colectivamente la vida de sus hijos - como tales, pero también como individuos que pertenecen a la comunidad social y política- y un castigo para los culpables, ellas denuncian el modelo de mujer pasiva y la sacralización angelificante de la función maternal, por tanto, atentan, en términos de Derrida, contra el poder de consignación del archivo dictatorial. Es por ello que el Estado las censura, desacredita, reprime y violenta - han sido encarceladas, secuestradas, desaparecidas, acusadas de locas - con el objeto, entre otros, de silenciar su combate contra la expropiación, colonización y objetivación de los cuerpos femeninos.

En virtud de lo desarrollado, sostengo que Demitrópulos crea un discurso subversivo al propuesto por el archivo de su contexto de producción. Esto es logrado gracias a una resemantización de la categoría de adorno, reveladora de la lucha política de María y base sobre la cual Isabel despliega su habilidad literaria. El adorno y sus texturas ya no simbolizan el silenciamiento femenino, ni provocan el deseo sexual en los hombres, ni vuelven pecadora a la mujer; aquí son un lenguaje que la reconcilia con su cuerpo, que la pone en diálogo con su madre y que forja un pasado que descubre que ella, a pesar de haber existido en un mundo de hombres, tuvo voz, luchó por su vida y supo sobrevivir en libertad. La nueva poética sobre el adorno imprime en la novela una huella femenina que elabora subjetividades transgresoras de la mujer, alternativas con respecto a las vigentes en el archivo oficial, al cual asedia y cuyo poder disputa. 


\section{Q Bibliografía}

» Abbate, F. (2015). Libertad Demitrópulos: Una narrativa de los vencidos: En torno a Sabotaje en el álbum familiar. Disponible en: https://amerika.revues. org/6237

» Aristóteles. Política (1971). Marías, J. (trad.). Madrid, Centro de Estudios Políticos y Constitucionales.

"Bunster, X. (1991). Sobreviviendo más allá del miedo. En Bunster, X.; Enloe, C. y Rodríguez, R. (eds.). La mujer ausente, pp. 41-62. Santiago de Chile, Isis internacional.

" Bracamonte, J. (2016). Narración histórica, memoria y arqueología del sujeto en Río de las congojas. Landa, 꾸. 1: 138-158.

»Calabrese, E. (1994). Historias, versiones y contramemorias en la novela argentina actual. En Calabrese, E. (ed.). Itinerarios entre la ficción y la historia. Trandiscursividad en la literatura hispanoamericana, pp. 53-73. Buenos Aires, Grupo editor latinoamericano.

" Campanella, H. N. (2003). Mito y leyenda en la novela histórica: Río de las congojas, de Libertad Demitrópulos. En La novela histórica argentina e iberoamericana, pp. 112-125. Buenos Aires, Vinciguerra.

»Demitrópulos, L. (2009). Río de las congojas. Buenos Aires, Ediciones del Dock.

»Derrida, J. (1997). Mal de archivo, una impresión freudiana. Madrid, Trotta.

»Didi-Huberman, G. (2008). Cuando las imágenes toman posición. Madrid, A. Machado Libros.

»Domínguez Rubio, N. (2007). De dónde vienen los niños. Maternidad y escritura en la cultura Argentina. Rosario, Beatriz Viterbo.

" Favoretto, M. (2009). La alegoría y la multiplicidad de significados en la novela histórica: Río de las congojas de Libertad Demitrópulos. En Alegoría e ironía bajo censura en la Argentina del Proceso, pp. 70-89. Estados Unidos, Edwin Mellen Press.

" García, A. M. (2005). Contar la Historia desde el margen en Río de las congojas de Libertad Demitrópulos y La pasión de Jeannette Winterson. Disponible en: http://www.geocities.ws/aularama/ponencias/gh/garcia.htm

» Ginzburg, C. (1999). Mitos, emblemas, indicios: morfología e historia. Barcelona, Gedisa.

" Gómez, M. D. (2009). El género en el cuerpo. Revista de Antropología, no 15 : 289-306.

» Hesíodo. (1982) [70o a.c]). Los trabajos y los días. Pérez Jiménez, A. y Martínez Díaz, A. (trads.). Madrid, Gredos.

» Irigaray, L. (1985). El cuerpo a cuerpo con la madre. Cuadernos Inacabados, no 24: 5-17.

"Jelin, E y Kaufman, S. (2000). Los niveles de la memoria: reconstrucciones del pasado dictatorial argentino. Entrepasados, no 20-21: 9-34.

" Knibiehler, Y. (2001). Historia de las madres y de la maternidad en Occidente. Buenos Aires, Nueva visión. 
"Ludmer, J. (2002). Temporalidades del presente, en la familia un sujeto público privilegiado. Boletín, no 10: 92-112.

»Mónaco, R. (2002). Río de las congojas, de Libertad Demitrópulos: cuestiones de textualidad y género. Cuadernos para investigación de la literatura hispánica, no 27: 411-416.

"Nallim, A. (2008). Territorios identitarios en la narrativa de Libertad Demitrópulos: una cartografía viajera. Tesis doctoral inédita. San Miguel de Tucumán, Universidad Nacional de Tucumán, Facultad de Filosofía y Letras.

»Palermo, Z. (1982). Río de las congojas de Libertad Demitrópulos: de la historia al símbolo. Buenos Aires, Centro de estudios latinoamericanos.

"Pérez Molina, I. (2004). La normativización del cuerpo femenino en la Edad Moderna: el vestido y la virginidad. Espacio, Tiempo y Forma. Serie IV, Historia Moderna, no 17: 103-116.

"-------. (2012). Apariencia del cuerpo y belleza: el adorno femenino. En La diferencia de ser mujer. Investigación y enseñanza de la historia. Disponible en: http://www.ub.edu/duoda/diferencia/html/es/secundario6.html.

"Poderti, A. (2000). La Literatura del Noroeste Argentino. Desde la Colonia hasta finales del siglo XX. Salta, Consejo de Investigación, Universidad Nacional de Salta.

»Portelli, A. (2014). Las funciones del olvido: escritura, oralidad y tradición. En Flier, P. y Lvovich, D. (coords.). Los usos del olvido: recorridos, dimensiones y nuevas preguntas, pp. 39-59. Rosario, Prohistoria.

»Ramírez, C. (2010). Literatura e historia; femenino y masculino: desestabilizaciones de un discurso. En Cossio, G.; Errázuriz, R.; Lagos, F. y López, N. (eds.). Prácticas culturales, discursos y poder en América Latina, pp. 163174. Santiago, Centro de Estudios Culturales Latinoamericanos.

» Rivera Garretas, M. M. (1996). Significados de la belleza del cuerpo: la cuestión del adorno femenino. El cuerpo indispensable: significados del cuerpo de la mujer. Cuadernos inacabados, № 24: 59-71.

» Tieffenberg, S. (1993). El espacio textual de una mujer: análisis de Río de las congojas de Libertad Demitrópulos. Actas II. Buenos Aires, Instituto de Filología y Literaturas Hispánicas “Dr. Amado Alonso".

"------. (1996). Libertad Demitrópulos, la escritura de la historia. Revista del Centro de Letras Hispanoamericanas, no 6-7-8: 611-617.

»Wolf, N. (1991). El mito de la belleza. Barcelona, Emecé.

» Young, I. M. (1990). On Female Body Experience: "Throwing Like a Girl" and Other Essays. New York, Indiana University Press.

"Zambrini, L. (2018). Modos de vestir e identidades de género: reflexiones sobre las marcas culturales en el cuerpo. Nomadías, ํำ11: 130-149. 
